\title{
Research on the Application of Heuristic Teaching Method in Single Chip Microcomputer Interface Technology and Application Course Teaching
}

\author{
Wang Yingying \\ Department of Electronic Engineering \\ Changchun Institute of Engineering Technology \\ Changchun, 130117, China \\ wyywyqn@163.com \\ Wei Jianhui \\ Department of Electronic Engineering \\ Changchun Institute of Engineering Technology \\ Changchun, 130117, China
}

\author{
Gao Qiang \\ Department of Electronic Engineering \\ Changchun Institute of Engineering Technology \\ Changchun, 130117, China \\ Jin Dingyun \\ Department of Electronic Engineering \\ Changchun Institute of Engineering Technology \\ Changchun, 130117, Chin
}

\author{
Ren Yueou \\ Department of Electronic Engineering \\ Changchun Institute of Engineering Technology \\ Changchun, 130117, China
}

\begin{abstract}
If asking questions equals to the application of the heuristic teaching method in teaching process, obviously, it is the misunderstanding of the application of the heuristic teaching method. Heuristic teaching method refers to a teaching method that the instructor raises questions and solves problems from the shallower to the deeper, from the near to the distant, from the outside to the inside and from the easier to the more advanced and leads students to grasp the knowledge actively, positively and consciously according to the textbook contents and student's cognitive rules. The essence of the heuristic teaching method should be guidance and it is the specific embodiment of the educational concept of "giving priority to learning". British educator Wald thought: "mediocre teachers only describe, good teachers explain, excellent teachers demonstrate and great teachers enlighten." It becomes an appraisal standard for instructors whether they can use the heuristic teaching method or not. This paper mainly studies "heuristic" teaching method and takes the teaching design of "MCS-51 single chip interrupt system" as an example and analyzes the specific application of "heuristic" teaching method.
\end{abstract}

Keywords-heuristic; interrupt system;teaching design; Teaching method

\section{What Is HeURISTIC TEACHING}

Is asking questions heuristic teaching? If asking questions equals to the application of the heuristic teaching method in teaching process, obviously, it is the misunderstanding of the application of the heuristic teaching method. Heuristic teaching method refers to a teaching method that the instructor raises questions and solves problems from the shallower to the deeper, from the near to the distant, from the outside to the inside and from the easier to the more advanced and leads students to grasp the knowledge actively, positively and consciously according to the textbook contents and student's cognitive rules. The essence of the heuristic teaching method should be guidance and it is the specific embodiment of the educational concept of "giving priority to learning". British educator Wald thought: "mediocre teachers only describe, good teachers explain, excellent teachers demonstrate and great teachers enlighten." It becomes an appraisal standard for instructors whether they can use the heuristic teaching method or not.

In the teaching process of 《Single Chip Microcomputer Interface Technology and Application》 and 《The Access database system application 》 Course, the instructor can achieve a satisfactory result by using the heuristic teaching method.

\section{HEURISTIC TEACHING METHOD IN THE APPLICATION OF "SINGLE CHIP MICROCOMPUTER INTERFACE TECHNOLOGY AND APPLICATION" COURSE}

\section{A. The Teaching Design of "MCS-51 Single Chip Microcomputer Interrupt System" Based on "The Heuristic Teaching Method"}

1) Analysis of the students' learning situation

"MCS-51 single chip microcomputer interrupt system" is an important part of Single Chip Microcomputer Interface 
Technology and Application Course for the sergeant students, the sergeant students generally have a good academic basis and have certain ability of analyzing and solving the problems, and they have a strong thirst for knowledge, rich in associative thinking and suitable for the heuristic teaching method.

"MCS-51 single chip microcomputer interrupt system "is very important knowledge of the Single Chip Microcomputer Interface Technology and Application, just because the interrupt system, the single chip microcomputer has the function of real-time processing, and only grasp the related knowledge of interrupt system can students truly understand what is interrupt and how to use it. Before this knowledge, students have grasped the definition of the interrupt and have a general knowledge of the interrupt but they haven't contacted with the process of the interrupt, the essence of the interrupt and the application of the interrupt, and if the students want to reach the level of using their knowledge of interrupt system, the knowledge in this class is an indispensable part and it urgently needs students to study[1].

\section{2) Analysis of the learning contents}

"MCS-51 single chip microcomputer interrupt system "is the 5th chapter of the Single Chip Microcomputer Interface Technology and Application, through analysis, the learning contents in this class mainly includes: (1)the basic definition of the interrupt;(2)the processing procedure of the interrupt;(3)MCS-51 single chip microcomputer interrupt system and application. The key teaching point in this class is the processing procedure of the interrupt. The teaching difficulty is the application of the interrupt.

\section{3) Analysis of the teaching objectives}

According to analysis on the student's learning situation and the teaching contents, the objectives of this class should be achieved :(1)the students can use their own language to describe the processing procedure of the interrupt;(2) the students should have the ability of using the interrupt to solve the problems;(3)Through the learning of the process procedure of the interrupt, foster students ability of problem-analyzing and problem-solving, enlighten them with the thinking mode of drawing inferences about other cases from one instance and gradual promotion, motivate their the spirit of exploration of overcoming the difficulties[2].

\section{4) Analysis of the teaching method}

The main teaching method in this class is "the heuristic teaching method", the flat interrupt system and its application dwell in the heuristic teaching method, makes the students grasp each step of the whole processing procedure of the interrupt progressively, from the shallower to the deeper. In the teaching process, the students concentrate on, they not only think actively and solve the problems actively, but also can apply the knowledge obtained in actual operation, which benefits to the cognition of the new knowledge and new things.

\section{5) The application of the teaching means}

The teaching equipment applied in this class is traditional blackboard, chalk and modern multimedia equipment. The former can present the important and difficult contents in this class, which conducive to the students' understanding and memory, and the later can provide much information and can set up and adjust query, which conducive to the students' intuitively grasp.

\section{B. The Main Teaching Process of the hing Design Based On "MCS-51 Interrupt System"}

1) Using example in real life leads out the definition of the interrupt

Using students' very familiar "on duty" phenomenon in their life, that is, One is reading a book on his duty when suddenly the telephone bell rings, at this time, the process of reading book is interrupted and the person on duty answers the phone, this is a typical "interrupt" phenomenon. Using this example which closes to students' life can naturally enlighten student's thought and lead them to understand the definition of the interrupt in single chip microcomputer.

2) Layer-Layer progressive, asking four questions to lead the students to grasp the main contents in this class

Through the study of the first step, the students can understand the definition of the interrupt, at this time, according to the definition of the interrupt the first question "how can single chip microcomputer identify the interrupt source?" after the first question, then we can raise up "what should we do if multiple interrupt sources send out the interrupt application at the same time? Which will CPU choose to provide service?", "Once CPU started the interrupt service, what specific operations will it make? That is to say, what kind of the process of the interrupt is?" Finally, how can we use the 51 single chip microcomputer complete the operation of the processing of the interrupt. Through raising up, analyzing and answering four questions, the students are guided and enlighten to follow the instructor's thought, from the shallower to the deeper, layer-layer progressively learn the important contents in this class.

Through the processes of raising up questions, analyzing questions and solving the problems, foster students thinking habit of the independent thinking, the divergent thinking and train their quality of overcoming the difficulties.

\section{Teaching reflection}

The objective of learning this class is to make students grasp the processing procedure of the MCS-51 single chip microcomputer interrupt, and then use the MCS-5single chip microcomputer interrupt system to deal with related interrupt incidents and make hardware design and programming application. Therefore, the key point is to make students grasp the three steps of processing interrupt, that is, the interrupt correspondence, interrupt processing and interrupt return, only master the processing method of three steps, can naturally use MCS-51single chip microcomputer interrupt system to complete practical application. The teaching design of this class is to raise up question as entry point and motivate student's thirst for knowledge. Finally, make asking questions and practice on class as stance, check student's effectiveness of learning. Thus use problem-solving method of gradually enlighten, step by step, circles within circles, to get a better teaching result. 


\section{APPLICATION OF HEURISTIC TEACHING METHOD IN THE COURSE OF APPLICATION OF ACCESS DATABASE SYSTEM}

Query is very important in the application of database system, and it is the concrete embodiment of the strong function of database system. This knowledge before the students have mastered the basic knowledge of database establishment and maintenance, a basic understanding of the use of the database, but the powerful database query function of the application has not been in contact with, to think of database to apply their knowledge level queries are not less than the knowledge of the importance of, this is where needs of students need to learn.

The teaching content of "the creation method of inquiry" mainly includes:(1) Create a simple query using the wizard;(2) Create a simple conditional query using the design view; (3) Use the design view to create a query for complex conditions. The teaching focus of this section is: to create a query using the design view。 Teaching difficulty is: use the design view to create complex conditions of the query.

Based on the heuristic teaching method "create the query method" teaching design process and a example is similar, this will not repeat them, below the main elaboration to the access database application, for example, elaborated "query creation method" in the Query Wizard and query designer use the main teaching process[3].

\section{A. Use the wizard to create a simple query}

case 1 , a query is set up, which is called a query 1 , according to the student table.

This is a very simple query establishment, only to guide the students according to the Query Wizard step by step to choose the required content to build the query, here is mainly to enable students to be familiar with the Query Wizard interface.

Method: click the query button in the "object" area, and then double-click the "use wizard to create the query", according to the wizard to set up.

After the completion of this problem, the students can experience the use of the wizard to establish the convenience of the query, followed by a case of two teachers, students are required to solve.

\section{B. Use the query designer to create a simple query}

[case two] a selection query based on the student table is established for a query 2: the number and name of the student who is older than 25 years of age.

In the case of a query, there are no restrictions on any query terms, but two is added to the query conditions. Then, can you use the Query Wizard to set up the query? The problem put forward, students will doubt that it is good to guide the review the wizard to create the query process, and at the same time, the use of multimedia equipment for demonstration, the students will pay attention to in using the wizard to create the query process did not set the query conditions, will not be able to use the Query Wizard to complete the ontology. The original road, the students will naturally want to find another way out, this time the teacher leads to the use of the query designer, and focus on the extraction of the three elements of the query. Since there is a demand for example two, the students will have a strong desire to learn about the query designer, the natural will be interested in the teacher's explanation of the query designer. Since there is a demand for example two, the students will have a strong desire to learn about the query designer, the natural will be interested in the teacher's explanation of the query designer. The so-called "interest is the best teacher", with interest in learning, students will naturally be impressed on the contents of the teacher's teaching. With theoretical knowledge, guide the students to use the query designer to complete the requirements of two.

Through such a problem, analysis of the problem, problemsolving process, to cultivate students' independent thinking, divergent thinking habits, hone their courage to overcome the difficulties of quality.

\section{Using query designer to build complex query}

[case three] a selection query based on the table of the student's table is established, which is a 3 year old male student or the name and gender of the female student who is admitted to 91 years ago.

The problem phase ratio increased condition complexity, before solving teachers to deal with the query condition analyze the comparison, the previous knowledge as bedding, coupled with the teacher inspired guide, students naturally will be able to use the query designer to build three cases of queries.

\section{Teaching reflection}

Whether the Query Wizard or query designer, the purpose of its establishment is the same, the specific choice of what should be based on specific circumstances, so to focus on the students to grasp the three elements of the query, as long as the three elements extracted from the query, it is natural to use the appropriate tools to establish a query. The teaching designs of the class is in the process of teaching take gradually inspired and deepen step by step, interlocking methods to solve problems, good teaching effect is achieved[4].

\section{CONCLUSION}

"The heuristic teaching method" is the embodiment of the educational concept of "giving priority to learning", through application in actual teaching, this method gives full play to student's subjective initiative, develop their ability of observing the questions, analyzing the questions, solving the problems and make teaching effect clearly promoted. But there are some certain deficiencies in teaching process, because this method has certain requirement on students' learning basis, for those students with poor basis may fall behind instructor's guidance progress and result in different degree of receiving knowledge among students. For those students with poor basis, the instructor should combine with other teaching methods according to the specific situation; give them more affirmation and encouragement. 


\section{REFERENCES}

[1] Gao Xinqi,Discussion on the related questions on online education teaching[J],2007(1). (In Chinese)

[2] Shi Xiujuan, Jin Jubo. Discussion and practice of course reform of Computer Culture Basis[J].vocational technology, 2006(2). (In Chinese)
[3] Dong Changhong. MATLAB Neural Network and Application [M] Beijing: National Defense Industry Press, 2005. (In Chinese)

[4] Wang Binhui, Multivariate Statistical Analysis and R Language Modeling [M] Jinan University Press, 2010. (In Chinese) 